\title{
Health Research in JFEI Over a Decade: 2009-2019
}

\author{
Anoshua Chaudhuri ${ }^{1}$
}

Published online: 7 September 2020

(c) Springer Science+Business Media, LLC, part of Springer Nature 2020

\begin{abstract}
This article is a review of thirty health-related articles published in the Journal of Family and Economic Issues from 2009 until 2019. This review discusses how the thirty studies have addressed broad areas of concern around health care access, health utilization and health status as well as health policy and implications and contributed to the advancement of knowledge in these areas. Articles mostly focused on health outcomes for families or demographic groups within families, with an emphasis on socio-economic inequalities and inequitable burdens faced. The emphasis over the last decade has been research on chronic or non-communicable health conditions and none on communicable diseases.
\end{abstract}

Keywords Health care access $\cdot$ Health utilization $\cdot$ Health status $\cdot$ Health behaviors $\cdot$ Health policy

\section{Introduction}

Health is one of the most important assets for an individual and family. Healthy individuals contribute productively to the economy and sustain the household. This year of 2020 has brought on a debilitating global pandemic that has made the topic of health even more poignant and has reminded us to not take our individual health, health care systems, public health infrastructure or our health care workers for granted. Contracting the COVID-19 virus could be distressing for individuals and their families but not having access to health care to treat it or not being able to afford the treatment would be catastrophic. Individuals may not get access to health care either due to unavailability of health care facilities, personnel and equipment but also due to denial of care from lack of insurance or finances. Not everyone has equal access to health care. Price of care, willingness to pay as well as income and ability to pay of patients are important determinants of access. Access to health care that is affordable allows individuals to look after themselves, maintain

This is one of several papers published together in Journal of Family and Economic Issues on the "Special Issue on Virtual Decade in Review".

Anoshua Chaudhuri

anoshua@sfsu.edu

1 Department of Economics, San Francisco State University, 1600 Holloway Avenue, San Francisco, CA 94132, USA good health and live a decent life. Thus, issues of access and affordability are at the heart of any health care discussion.

Looking through a decade of research on health, numerous papers examined the determinants of affordable access to health care, health utilization patterns across the life span, reasons for positive and negative health behaviors, individual health status, financial burden from trying to maintain good health as well as socioeconomic determinants of health. Family is the focus of the journal and all the papers published contributed to health-related studies around the family and the life course. Some papers looked at the family as a whole but most papers focused on certain demographic groups such as children and elderly. The journal has published both domestic and international studies. About twenty percent of the papers published during the last ten years looked at health related questions in populations outside the US. This international perspective is valuable not only to learn about other contexts but also to remind ourselves that some of these issues are universal. The most important health and nutrition programs and policies of the decade have been studied and evaluated. Researchers have used a wide variety of data, including census data, nationally representative survey data, administrative data, as well as individually collected quantitative and qualitative survey data spanning 40 years. A summary table is provided for a visual of the diversity of data sources used by papers accepted for publication over the past decade (Table 1). While describing the contributions and findings from the 
Table 1 Data used in the articles published between 2009 and 2019

\begin{tabular}{|c|c|c|}
\hline Dataset & Time-period & Citation \\
\hline \multirow{4}{*}{$\begin{array}{l}\text { Bureau of Labor Statistics, } 1979 \text { National Longitudinal Survey } \\
\text { of Youth }\end{array}$} & $1982-1983$ & Miller (2011) \\
\hline & $1985-2002$ & Zhang et al. (2011) \\
\hline & $1987-1996$ & Chen and Zhang (2011) \\
\hline & $1998-2002$ & Chen and Zhang (2011) \\
\hline $\begin{array}{l}\text { Massachusetts Division of Health Care Finance and Policy } \\
\text { Acute Hospital Discharge Data }\end{array}$ & 1994-2002 & Brandt and Marie (2011) \\
\hline \multirow[t]{5}{*}{ Medical Expenditure Panel Survey (MEPS) } & $1996-2006$ & Witt et al. (2011) \\
\hline & 1996-2002 & Zimmer (2011) \\
\hline & $2000-2007$ & Chang et al. (2011a, b) \\
\hline & $2001-2008$ & Monheit and Vistnes (2015)—(MEPS-HC) \\
\hline & 2004-2008 & (Roby et al. 2013) - (MEPS-HC) \\
\hline \multirow{2}{*}{$\begin{array}{l}\text { Early Childhood Longitudinal Study-Kindergarten Class } \\
\text { (ECLS-K) }\end{array}$} & \multirow[t]{2}{*}{ 1998-1999 } & Capogrossi and You (2013) \\
\hline & & Murasko (2015) \\
\hline Early Childhood Longitudinal Study-Birth Cohort (ECLS-B) & 2001 & Murasko (2015) \\
\hline \multirow[t]{2}{*}{ Health and Retirement Study (HRS) } & $1992-2010$ & Shin and Kim (2018) \\
\hline & 1998-2004 & Kim et al. (2012) \\
\hline Elderly Nutrition and Health Survey in Taiwan (ENHST) & $1999-2000$ & Chang et al. (2010) \\
\hline \multirow[t]{3}{*}{ Panel Study of Income Dynamics } & 1999, 2001, 2003 and 2005 waves & Grafova (2011) \\
\hline & $2007-2008$ & $\begin{array}{l}\text { Benson and Mokhtari (2011) Child Devel- } \\
\text { opment Supplement (CDS) }\end{array}$ \\
\hline & 2011 & Richard (2016) \\
\hline \multirow[t]{2}{*}{ American Community Survey (ACS) } & 2003-2009; excluding 2006 & Yaskewich (2015) \\
\hline & 2005-2009 & Roby et al. (2013) \\
\hline March Current Population Survey (CPS) & 2003-2009; excluding 2006 & Yaskewich (2015) \\
\hline $\begin{array}{l}\text { American Chamber of Commerce Researchers Association } \\
\text { Price data }\end{array}$ & $\mathrm{n} / \mathrm{a}$ & Zhang et al. (2011) \\
\hline National Health Interview Survey (NHIS) & April and August 2005 & Lin et al. (2012) \\
\hline National Health Survey of 12 years old and under (NHS12) & 2005 & Ho and Hung (2013) \\
\hline California Health Interview Survey (CHIS) & 2009 & Roby et al. (2013) \\
\hline $\begin{array}{l}\text { Survey of Foreign and Mainland Chinese Spouses Living } \\
\text { Demand (SFSLD) }\end{array}$ & Mid november 2008 & Ho and Hung (2013) \\
\hline $\begin{array}{l}\text { Household expenditure data collected by the Turkish Statistical } \\
\text { Institute (TSI) }\end{array}$ & 2015 & Aksoy et al. (2019) \\
\hline $\begin{array}{l}\text { California subset of the Employer Health Benefits Survey } \\
\text { (CEHBS) }\end{array}$ & 2010 & Roby et al. (2013) \\
\hline
\end{tabular}

thirty health papers, extensive reference to health studies published outside the journal was made to provide a context to these contributions. Limitations of the studies were broadly discussed and questions that remain were explicitly mentioned to inspire the reader with new research ideas.

In this review article, focus was on areas of concern such as healthcare access, utilization, health outcomes, socio-economic inequalities, inequitable burdens as well as health policy and implications. The purpose was to discuss how these thirty published studies have addressed these concerns and contributed to the advancement of knowledge in each of these areas.

\section{Health Care Access}

Access and affordability of health care services have been at the forefront of any public discourse on health, and policy suggestions have revolved around finding solutions to reduce the numbers of people who either do not have access to health care services or cannot afford to pay for health care. Hence, studies have tried to determine the important reasons for the lack of access to health care. One of the biggest barriers to health care access in the United States is the lack of insurance. With a third-party payer system in the United States, those who may not have health insurance often have difficulty accessing health care. Even 
those who have health insurance may be under-insured or may not fully understand their coverage and rights. Prior to the Patient Protection and Affordable Care Act (ACA) of 2010, 15\% of Americans were uninsured and these numbers were rising (Tolbert et al. 2019). Dolan and Mokhtari (2013) point to inherent complexities of ACA and its challenges for providing coverage and lowering costs. They also note "...the economic consequences of such an important overhaul by a complex law may depend not only on the fine details of the law and subsequent regulations but also on the regulators and what they beneficially implement in their uncontested domains." Hence, with the ACA about to go into effect in 2014, it was important to set up health insurance literacy programs and have insurance navigators to help people understand and navigate the new system and sign up for their mandatory insurance.

Bartholomae et al (2016) evaluated a health insurance literacy program to see its impact on access to health care and found that young adult consumers were not receptive to health-related information. Expecting to be in good health, young people did not find health insurance literacy to be relevant or important. States that were supportive and ready to implement the ACA actively developed websites and materials to reach uninsured consumers and ramped up their outreach and marketing efforts as well as enrollment strategies. Men in Bartholomae et al.'s sample may have had limited experience with health insurance and being greater risktakers were less involved and interested. Women achieved greater gains to health insurance literacy compared to men. The study concluded that consumer education to target young adults with a relevant message, as well as educational programming and informational outreach with consideration towards gender differences, could help increase awareness and access across diverse groups. Health care costs continue to rise and increasingly play a pivotal role in a family's budget. Uninsured families, low-to-moderate income families, and families with children report higher medical bills and medical debt. Hence, the study recommended that insurance literacy programs were also an opportunity to increase awareness and understanding of ways in which families, particularly the vulnerable populations as identified above, can reduce their health care costs.

Lin et al. (2012) looked at the impact of family structures (nuclear and multi-generational households) on Taiwanese children's access to preventive care when insurance and access was already available through Taiwan's national health insurance (NHI). NHI is a single-payer compulsory social insurance plan that provides equal access to healthcare for all Taiwanese citizens. NHI is mainly financed through premiums, paid for through payroll tax, and is supplemented with out-of-pocket payments and direct government funding. NHI covers well-baby care and all primary immunizations for children under 7 years old. However, vaccinations for Hep A, Influenza, chicken pox, DPT, and others recommended by public health authorities are not covered by NHI. This study wanted to understand if families with single parents, two parents, or grandparents differed significantly in their demand for non-free vaccines, wondering whether time price of taking children to the doctor or the price of vaccines was the determining factor. Controlling for various health, demographic and socio-economic factors, the study found that financial constraints played a more important role in the decision to give children vaccines that were not free, whereas family structure and parental opportunity costs were not significant. This strongly suggests that if all vaccines were free, it would increase access to preventive care for all Taiwanese children, particularly those from low-income families. This is a question not only for the Taiwanese context but of relevance for the US as well. The policy suggestion that low-income families should be provided vaccines for free is pertinent for the US and the rest of the world, particularly in the aftermath of the current pandemic, specially to achieve higher compliance with public health directives.

There could be positive spillover effects of public provision of health insurance for children through programs such as the state child health insurance program (SCHIP), on other family members' access to health care. This is the question explored in the Monheit and Vistnes (2015) paper which found that the uninsured, low-income single mothers with children enrolled in public coverage used more preventive and other health care services than their counterparts who did not enroll their children in such coverage. Although this study did not find much evidence that mothers increased their health care use because of the savings they experienced, they found that there was an increased likelihood of using preventive tests and services as well as medicines. These results were robust even after controlling for the potential endogeneity bias arising from the correlation of enrolling children in public coverage and mother's own propensity to use health care services.

Since its inception in 1997, SCHIP allowed dependent children to have health insurance until 19 years of age in most states but there were state-level variations in this age cut-off, and some states covered young adults up to age 24 provided they were full time students. ACA increased the age cut-off of dependent children on parents' health insurance to 26 years. Yaskewich (2015) examined whether such dependent age laws affected college enrollment, a question which previous literature had not addressed. A contribution of this paper was the use of variations in the dependent insurance mandates on health insurance coverage, using a two-state comparison between New Jersey (NJ) and Pennsylvania (PA) that provided a neat quasi-experiment that allowed for a difference-in-difference analysis. The New Jersey-Pennsylvania comparison allowed Yaskewich to compare a lenient state $(\mathrm{NJ})$ versus a strict state $(\mathrm{PA})$ and 
show that insurance coverage increased in New Jersey across all youth ages and income groups while college enrollment actually dropped for White students and those who could be on their parent's health insurance plans, compared to those in Pennsylvania. However, for youth in lower income groups in New Jersey, college lock (forced to keep full-time student status) remained because they were less likely to have dependent insurance and had to show full-time college enrollment to qualify for health insurance through Medicaid or SCHIP.

Another study on health care access, by Chang et al. (2011b), looked at the important question of declining farming population in the US and used Medical Expenditure Panel Surveys (MEPS) data to show that having health insurance was more important than income and demographic variables in enabling farmers to remain in farming. Physical health problems and worsening perceived health were high predictors of leaving the farming business. However, having private health insurance encouraged farmers with physical health problems to stay in the farming business and allowed them to avoid putting in extra time and effort to invest in establishing a new career.

With a rapidly aging population, Kim et al. (2012) provided useful knowledge about who is at higher risk of using home care services and who has unmet need for home care services by exploring the determinants of access to long term care insurance (LTCI) and LTC utilization in the period 1998-2004. They found that either those with higher incomes or those with Medicaid eligibility had access to long-term care. However, they did not find any evidence of moral hazard (or over use) behavior in the long-term care market.

\section{Health Utilization}

Doctor visits, hospitalization and lengths of stay are some of the common measures of health utilization. Brandt and Marie (2011) measured asthma related hospital stays and readmissions and found statistically significant reduced stays among non-Whites compared to Whites. The authors did not see any impact of length of stay on re-admission rates. Other studies found that availability of public insurance such as SCHIP increased health utilization among children (Zimmer 2011) and increased preventive medical care for mothers (Monheit and Vistnes 2015). Kim et al. (2012) found that income, homeownership, and living with children had a significant negative effect on home care utilization but activity limitations and functional disabilities increased the likelihood of using home care. After controlling for endogeneity between LTCI ownership and home care utilization, they found that having insurance did not increase the likelihood of using home care. A question identified by the study that warrants further research, is to see how LTCI ownership changes the utilization patterns of different types of LTC services and how these patterns vary by gender.

Fan et al (2013) examined the impact of domestic migration within China on health utilization and found that female migrants in China and male locals both had significantly lower healthcare utilization rates, compared to female locals. "Female migrants were more likely to report "no money" as a reason for not seeking care, while male locals were more likely to report "self-medication" as a reason" (Fan et al. 2013, p. 52). All citizens of China have basic health insurance in the place that they are registered in, a system known as the hukou system. The health infrastructure in urban areas and major cities are vastly superior compared to those in the rural interiors. The hukou system maintains a spatial hierarchy between urban and rural residents creating an inequality and marginalization for rural to urban migrants especially with respect to social benefits and healthcare access. Although this is a situation unique to China, similar situations may arise for US residents migrating from one state to another especially because states vary in Medicaid eligibility rules and dependent care laws.

Since Roe v. Wade, women have been mostly able to exercise their right to abortion. However, this issue is highly political and women have often faced barriers to seeking abortion services through various restrictive state abortion laws such as no Medicaid funding, parental involvement laws, mandatory counseling laws, two-visit laws, and targeted restrictions on abortion providers (TRAP) laws. Researchers have evaluated the impacts of these laws on women's access and utilization of abortion services as well as on their physical and psychological wellbeing. What has not been studied very widely is the impact of anti-abortion criminal activity on the supply and demand of abortion services. Medoff (2015) used a unique data set and found that the threat of harm is a deterrent for abortion service providers, which in turn, harms those who seek legitimate abortion services. This study suggests the need to examine the number of anti-abortion criminal activities and/or restrictive state laws on the number of abortion providers over time.

\section{Health Behaviors}

Health behaviors encompass negative and positive behaviors that not only impact health outcomes but are also associated with external effects. We classify substance use and abuse as a negative health behavior that has negative effects on the user but also indirect effects on by-standers and society. Positive health behaviors occur when individuals educate and inform themselves and carry out health enhancing habits that have positive impacts on individuals, their families, and 
communities. Again, financial and social constraints affect these behaviors and may result in inequitable outcomes.

Chang et al. (2011a) studied the impact of improving dietary knowledge among Taiwanese elderly on nutrition deficiencies of the elderly and found significant gender differences in nutrient intake behaviors. The elderly are one of the fastest growing segments of the population, particularly in the developed world. In Taiwan, the percentage of elderly population is already at $15 \%$ with an increase of $65 \%$ of this demographic group between 1990 and 2007, giving it an "elder country" designation according to the United Nations (Chang et al 2011a). Using data from the Taiwanese Elderly Nutrition and Health Survey this study found that dietary knowledge is an important determinant of elders' nutrient intake status. They found that mental health affects female elders' nutrition whereas physical functions significantly influence male elders' nutrient intake. Instead of focusing on the nutrient intakes using binary models as done in previous studies, Chang et al. (2011a) focused on determining the profile of elderly who were more or less likely to follow the recommended dietary levels. These findings have significant implications for health policy for the elderly and warrant similar investigations in other contexts.

Grafova (2011) found that the onset of smoking was a result of financial strain for men but not for women, and equally for those who attended college as well as those who never attended college. Of course, financial strain is strongly associated with income and affects individuals more adversely in lower income families. Aksoy et al (2019) measured the socio-economic determinants of tobacco and alcohol consumption in Turkey to understand policy prescriptions that might work to reduce tobacco and alcohol use. Tobacco leads to"blending," i.e., reducing the household budget for other household expenditures, affecting other members of the household, as well as indirectly increasing health-care related expenditures. As the western countries have seen a decline in tobacco and alcohol consumption, the use of these products have in fact increased in the developing world, including Turkey. While research consistently suggest "sin tax" (Chaloupka 2013) and prices (WHO 2014) as effective policy tools to reduce smoking and alcohol consumption, this Turkish study brings a completely different perspective. The Turkish government as part of their Action Plan for National Control of Tobacco, in 2004, raised taxes on tobacco and limited the sale and availability of tobacco and alcohol products. Aksoy et al. examined the joint consumption of alcohol and tobacco and found that instead of a reduction, there was a $10 \%$ increase in consumption between 2013 and 2016. They found that those younger than 50 years of age, heads of household, singles, and those with less than college education were more likely to consume tobacco and alcohol. Because these Turkish smokers did not respond to a tax incentive, the authors suggested implementing alternative policies depending on the social and cultural context. Education about impacts on chronic conditions through health information campaigns and restrictions on marketing of these products were found to be more effective in a setting like Turkey. This study points to the importance of replicating these sorts of studies in different countries and contexts to build the knowledge about variations in consumer health behaviors so that effective and contextual policy making could take place.

While a large theoretical literature exists on the transmission of traits across generations, there has been little work so far on the specific transmission of (un)healthy lifestyles, and on the equilibrium prevalence of (un)healthy lifestyles in the long-run (Ponthiere 2011). Although lifestyles affect mortality, it is also possible that mortality affects lifestyles. Given this reverse causality, Ponthiere (2010) examined the prevalence of unhealthy life- styles over the long run. Using an overlapping-generations model, the study found that healthy lifestyles demonstrated an evolutionary advantage, uniquely due to the difference in life expectancy of individuals with healthy and unhealthy lifestyles. Parental concerns for children's health tended to raise the long-run investment in healthy agents, leading to greater long run prevalence of health lifestyles.

\section{Health Status}

Papers published in JFEI that evaluated health outcomes have focused on three main measures of health status. First, with the increased incidence of obesity in the United States, researchers have tried to understand the causes and consequences of obesity. Within the obesity literature, with childhood obesity on the rise, determinants of childhood body mass index (BMI) have been investigated extensively. Second, with increased longevity, sedentary lifestyles, and chronic illnesses are on the rise, the causes and consequences of chronic illnesses have been of interest. Third, a few papers examined self-reported health status to measure mental health, depression and health on an ordinal scale. All of these studies showcase the differential impacts as a result of socio-economic disparities, resulting in unequal burdens and social inequities in health outcomes.

\section{Obesity}

Obesity is a serious and costly disease in the United States. From 1999 to 2000 through 2017-2018, the prevalence of obesity increased from $30.5 \%$ to $42.4 \%$, and the prevalence of severe obesity increased from $4.7 \%$ to $9.2 \%$ (Hales et al 2020). The estimated annual medical cost of obesity in the United States was $\$ 147$ billion in 2008 US dollars and the medical cost for people who have obesity was $\$ 1,429$ higher 
than those of normal weight. Non-Hispanic Blacks (49.6\%) had the highest age-adjusted prevalence of obesity, followed by Hispanics (44.8\%), non-Hispanic Whites (42.2\%) and non-Hispanic Asians (17.4\%). The association between obesity and income or educational level is complex and differs by sex and race/ethnicity. Overall, men and women with college degrees have lower obesity prevalence compared with those with less education.

Even though one of the objectives of the food stamp program (FSP) was to provide a safety net to those with lower socio-economic status, studies have indicated that FSP participation has increased the incidence of obesity (Gibson 2003; Chen et al. 2005). Chen and Zhang (2011) built on the food stamp participation and obesity literature by drawing from nutrigenomics, which address how genetics plays a role in how ethnic groups metabolize foods and food groups. They looked at race and ethnicity variations in the incidence of obesity as a result of food stamp participation and found that Hispanics were disproportionately and adversely affected compared to other ethnic groups. In past studies, obesity due to food stamp participation was purely attributed to the "thrifty gene," binge eating, and over consumption. This paper provided a new angle, i.e., variations in metabolism of foods may affect certain ethnicities more adversely than others.

Zhang et al. (2011) also examined the impact of prices of unhealthy foods on obesity among food stamp participants and found that obesity, especially among low income people, increased in places where unhealthy foods were cheaper. This piece of research made an important contribution to the obesity literature and further asked two questions for future research: Would food stamp participants buy less food if they were given cash instead? Would taxes on unhealthy foods such as soda, foods with sugars and trans-fats reduce obesity?

\section{Childhood BMI}

Rising rates of obesity, especially in childhood, is a cause of concern in the United States as it is associated with a multitude of chronic diseases and poses a heavy economic burden (Ogden 2017). It is therefore fitting that several papers examined the possible causes of childhood obesity with a focus on factors related to the family.

Building on previous findings around increased childhood obesity due to increased maternal work hours in the labor market, Miller (2011) examined whether the timing of maternal work had any impact on children's obesity and whether this relationship varied by sub-groups. Timing of maternal work seemed to affect child obesity in the UK (Scholder 2008). In the US, using National Longitudinal Survey of Youth (NLSY) data, Miller (2011) found that maternal work at ages 9-11 and 12-14 was related to an increased rate of overweight during the same periods. This study also found that increased maternal work hours when children were aged 6-8 years led to decreased rates of obesity. Further, these results were pronounced for children in low-income families and with single mothers. This paper suggested that we ought to look at the developmental stages and age specific protective factors for obesity prevention efforts among children.

You and Davis (2011) examined the quality of childcare time spent by parents on childhood obesity in various age groups. They found that for the 9-11 years age group, a child's probability of being overweight or obese will be exacerbated if either of the parents is not involved with the child, but fathers appear to be especially important. Fathers' secondary childcare time has the largest marginal effect in reducing child obesity, followed by fathers' primary childcare time, and then mothers' primary childcare time. Both paternal and maternal disengaged/multi-tasking time with children also had an alleviating impact on childhood obesity in the 9-11 year age group but more so in the 13-15 age group.

Benson and Mokhtari (2011) used the Panel Study of Income Dynamics (PSID) to examine child obesity and its relationship to parental employment and time spent with children. They found that hours of parental employment was an important determinant of child obesity. Fathers' hours of work was more than two times more important than that of mothers and children who worked on building and repair projects with parents and regularly read with their parents had significantly lower BMIs. As parental work hours have increased and third-party childcare substituted parental time with children, a question worth studying would be the impact of third-party childcare on childhood obesity, by type and quality.

Further, Hayes et al (2016) explored the common understanding that maternal BMI influences childhood BMI through genetic transmission and found evidence of mediating factors that may affect this relationship. Their study suggested that minimizing stressors may act as a source of protection for children against obesity in the most vulnerable populations such as low-income and ethnically diverse families. By reducing perceived economic strain, overall stress experienced by a parent may reduce. This in turn might lower physiological reactions and improve healthy behaviors such as increased physical activity and more positive food choices among mothers resulting in a positive impact on children's BMI even if mothers were themselves overweight. Their study strongly advocated for greater collaboration between disciplines such as economics, family resiliency, genetics, human development, family studies, and nutrition behavior to inform holistic policy interventions around childhood obesity. 
Even with all the focus on the obesity epidemic and rising obesity prevalence in many regions of the world, the prevalence of underweight remains high (Abarca-Gómez et al. 2017). Childhood undernutrition is associated with sarcopenia, cardiac and renal dysfunction, and immunological defects and might cause as many as 3.1 million deaths annually ( $45 \%$ of all deaths of children worldwide). From 1975 to 2014 , the prevalence of underweight $\left(\mathrm{BMI}<5^{\text {th }}\right.$ percentile standard) in US children 2 to 19 years of age decreased from about $5.1 \%$ to about $3.8 \%$ (Fryar et al. 2016) still leaving about 3.5 million underweight children and teenagers in the US. This is a sizable population and should be of serious public concern because lower intake and poor absorption of vital nutrients tend to weaken immune systems and lead to frequent infections that result in underperformance for these children.

Capogrossi and You (2013) looked at the impact of childhood BMI on academic achievement. Weight (both overweight and underweight) might reduce ability, self-esteem, school attendance, and concentration, all of which may impact academic performance, and under-performance may reduce self-esteem which could then influence eating disorders or consumption of unhealthy foods leading to weight gain or loss. It is not clear whether weight affects academic performance or academic performance impacts weight issues. Prior to this paper, not much research existed on the impact of weight on academic performance in the United States (even though this is a common topic in other countries). This paper contributed to the literature by controlling for endogeneity from the possible reverse causality by using Instrumental Variable Quantile Regression (IVQR) method. They found that childhood BMI negatively impacts school performance for both the overweight and the underweight children, i.e., normal weight children do better on math and reading compared to under or overweight children. Most of the prior work on the relationship between child weight and academic performance focused on the effects of the "average" child. However, the authors make the point with their findings that the average effect has limited policy implications, and it is perhaps more important to know whether and how weight impacts those students at the lower end of the academic performance distribution. This paper made an important contribution by suggesting that maintaining healthy BMI for kids may help lower achievement gaps, especially between White and minority students, as Black and Hispanic students are more likely to be underweight or overweight.

\section{Chronic Illness}

Asthma is one of the most common chronic ailments that afflict Americans, particularly children. There are direct and indirect cost burdens on families in terms of care-related expenses, lost time at work, and impact on family wellbeing (Brandt and Marie 2011). Hospitalization related to asthma is expensive and this study by Brandt and Marie (2011) showed disparities in length of stay in the hospital by race and ethnicity. Whites on an average stayed longer whereas non-White patients had shorter hospital stays, even after controlling for endogeneity around severity of illness and payer type. An important contribution of this paper was looking at length of stay and hospital re-admissions: The authors found no statistically significant associations, which perhaps suggests that the race disparity in length of stay may not be the reason for poorer outcomes for non-White asthma conditions. However, this paper also advances the discussion on equity and justice around use of resources for Whites and non-Whites. If care is optimal for Whites, then non-Whites were getting less, perhaps leading to the disproportionately higher asthma related morbidity among nonWhites, whereas if non-Whites were getting optimal amount of care, then Whites were getting excessive care leading to greater and avoidable health care costs.

Witt et al. (2011) examined the financial burden on families that have children with activity limitations and showed that burdens were consistently higher for such families across income levels, in comparison to families without children with limitations. However, the authors also found that low-income families experienced a greater relative burden as defined by expenditures as a proportion of income. One mitigating factor was the availability of public insurance making a stronger case for supporting families with children, regardless of income or medical conditions. A related question of how the financial stress of looking after children with functional limitations impacted the ability of parents to look after their children further points to a need for availability of public insurance to alleviate these pressures for parents, especially low-income parents.

McCabe and O'Connor (2010) studied a sample of Australian patients with progressive neurological diseases and saw that the perception of economic hardship as a result of illness and illness-related expenditures negatively impacted the quality of life for patients. Even though the sample was small and purposive and the results were not entirely generalizable, the study highlighted the importance of subjective assessments of financial pressures in addition to objective measures such as expenses and incomes. Chronic and progressive neurological illnesses increase financial burden for patients and caregivers by increasing expenses and opportunity costs but these objective measures may be less important than the perceived measures, which can be greatly alleviated through social and emotional support (McCabe and O'Connor 2010). McCabe and O'Connor's article draws on literature from the US and Canada and its conclusions are not only valuable in the Australian context but has important lessons for the rest of the world, particularly that social 
support networks can help alleviate some of the economic pressures that impact the psychosocial functioning of those with chronic illnesses.

Shin and Kim (2018) used longitudinal data from Health and Retirement Study (HRS) to study the long-term impacts of chronic conditions of older Americans on their out of pocket (OOP) expenditure burdens over twenty years. They found that those with multiple or co-morbidities spent more than double the amount OOP than those with no diseases. Their study provides important implications both for consumers in choosing the right plans to manage their OOP burden as well as information for policymakers for managing and designing Medicare Part D program to prevent adverse selection.

\section{Self-reported Health Status}

In another study from Taiwan, Ho and Hung (2013) examined the health status of children born to immigrant mothers compared to native-born mothers. Health is measured as 'excellent', 'good' or 'average' as assessed by parents. The study found that children born to immigrant mothers are healthier than native mothers, with girls more likely to have better health than boys. Many foreign-born women come to Taiwan by way of marriage and thus the number of children born to immigrant mothers have increased making this an important question to investigate in the Taiwanese context. In the United States, children of immigrants have a health advantage known as the Hispanic paradox (Ruiz et al. 2013). This immigrant advantage holds strong in the UK as well.

Murasko (2015) used ordinal scales to measure children's health status with the help of maternal reports of their children's health. This study examined the income-health gradient at different ages of children building in dynamic changes in health and income, and showed that incomehealth gradients became steeper as children grew older from infancy to adolescence. The gradient had a larger magnitude with respect to current income rather than average income. Income exhibited weaker association with a more conservative definition of poor health. To contextualize these results, the study conjectured that the deprivation of low-income environments have long term effects on the probability of chronic conditions and the management of those conditions are strongly impacted by transitory changes in income, particularly in adolescence. Hence, the impact seemed to be greater at adolescence and current income matters more. The study also poses a critical lens on the use of maternal reports of child health as income and environment significantly affects how parents view and report health status.

Hunn and Heath (2011) examined, simultaneously, the effects of economic hardships and adverse life events on depression, and illustrated the role of depression as the mediating variable between life circumstances (caused by economic hardships and adverse life events) and employment or welfare use. Depression was measured using a scale constructed from respondent statements. This study asked for a rigorous examination of and solutions for barriers to successful transition from welfare to work in the presence of life circumstances affecting mental health status.

\section{Health Policy Implications}

Over the last 10 years, about half of the papers evaluated key programs and policies in the US, including the Patient Protection and the Affordable Care Act (PPACA), food assistance programs, welfare reform, and the state children's health insurance program (SCHIP). These papers addressed the potential direct and indirect effects on families from these programs and provided insight into policy implications for the future. Four studies have been described in previous sections of this review in the context of their health findings, and are now discussed in terms of their policy focus. These include Chen and Zhang (2011) and Zhang et al (2011) on child BMI, Hunn and Heath (2011) on depression, and Yaskewich (2015) on the relationship between health coverage and college enrollment. Other papers discussed in this section had a specific focus on particular health policies or programs.

The Supplemental Nutrition Assistance Program (SNAP) was instituted in 2008 to rename and de-stigmatize the former Food Stamp Program (FSP). Using FSP to provide continuity with the previous literature, studies found FSP participants to have a higher BMI than eligible non-participants with substantial racial and ethnic disparities in the effects of FSP participation (Chen and Zhang 2011; Zhang et al 2011). Further, Zhang et al. (2011) found that on average, FSP participants' BMIs were two points greater than the BMIs of nonparticipants and found greater obesity in regions with lower prices of unhealthy foods. This study provided suggestions to potentially increase the price of unhealthy foods or adjust FSP benefits based on regional prices of unhealthy foods to partially offset the undesired impact of FSP participation on BMI and obesity. The study also provided support for a tax on unhealthy foods to reduce incidences of obesity.

The Personal Responsibility and Work Opportunity Reconciliation Act (PRWORA) of 1996 was an attempt at welfare reform that ended the former Aid to Families with Dependent Children (AFDC) and created the Temporary Assistance to Needy Families (TANF) program. The TANF program was created with the intention to increase work, reduce dependency on welfare, reduce births outside marriage, and to increase the formation of two-parent families. However, welfare reform has been associated with reduction in health insurance coverage, increase in the likelihood of needing care but finding it unaffordable, with these effects 
somewhat larger for Hispanics compared with Blacks and low-educated women (Bitler et al. 2005). It is also negatively associated with self-reported health (Narain et al. 2017), and has led to a 3-5\% decrease in the likelihood that a child has an annual checkup (Vaughn 2019). Further, states with greater levels of welfare restrictiveness had higher rates of violent crime (Liebertz and Bunch 2017), exceeding time limits decreased probability of Medicaid coverage and provider contact and increased the probability of being uninsured (Narain and Ettner 2017). Consistent with this literature, Hunn and Heath (2011) found that economic hardships and adverse life events increased depression scores, depression reduced earnings, and increased use of TANF by eligible women. Chronic depression is overrepresented in the welfare population and the complexity of transitioning from welfare to work may exacerbate these conditions and create greater barriers. Hence, resources for mental health interventions, interventions to address depression due to economic hardships and adverse life events and time limit exemption for those with poor prognosis may help to prevent welfare recipients from remaining in poverty.

The next policy experiment that researchers looked into is the state children's health insurance program (SCHIP) that was first implemented in 1997 to help children in those families who earned too much to qualify for Medicaid but too little to afford private health insurance. In 2008, this program was expanded with more funding to cover an additional 4 million children. Zimmer (2011) provided an excellent review of the SCHIP program. The focus of this paper was to see the impact of expanding SCHIP on those who previously had private insurance and their health utilization patterns. The paper showed a crowd-out effect from private insurance into public insurance for about 1.3 million children. Their health utilization also increased but not because they were less healthy than those who did not switch to public insurance, but possibly because of unmet needs. This paper concluded that the expansion of SCHIP ended up being more costly than intended because of this crowd-out effect. Witt et al. (2011), on the other hand, discovered that families with children who had activity limitations incurred greater out-of-pocket expenditures, experienced greater economic burden, and may need affordable medical help. The only factor in their study that reduced child and whole family-burden was public health insurance, thus making a stronger case for SCHIP as a means to reduce financial burden for low-income families. Monheit and Vistnes (2015) found that single mothers, particularly, had extra resources to spend on preventive health care and spent less on mental health expenses when their children had health insurance through SCHIP.

Perhaps the most needed but most contentious health policy enactment was the PPACA of 2010, implemented in 2014. With 49 million uninsured Americans, the PPACA (or
ACA) was intended to address problems of under-insurance, denials of coverage for pre-existing conditions, and bankruptcy resulting from out-of-pocket medical costs. ACA was built on the current third-party payer system. It allowed those who already had insurance to keep their insurance, increased the age limit of children as dependents on parents coverage to 26 years, allowed Medicaid expansion in states that wanted it, created a health exchange marketplace for the uninsured to buy health insurance at a competitive rate and imposed an individual mandate of "play or pay". Further, insurance companies were prohibited from denying coverage based on pre-existing conditions or gender and were mandated to cover preventive care and other minimum care at free or low affordable rates. Thus, naturally over the last decade, at least five papers have directly addressed the ACA and examined specific impacts.

In anticipation that the new policy with its complexities would require marketing, outreach and health literacy, Bartholomae et al (2016) developed a health insurance literacy program and piloted it in seven states to establish a baseline grouping of high and low literacy levels. Their study laid some important guidelines for future consumer education by suggesting targeting younger adults, being cognizant of gender differences and the need for individuals to understand the nuances around their insurance eligibility. They also showed that the states who were supportive of implementing ACA were already actively developing outreach campaigns. Roby et al. (2013) provided a very good description of the constraints around ACA and need for state-level analysis by examining the consumer experience in California with a focus on who would be most likely to adhere or not adhere to the individually mandated minimum coverage requirement (MCR). Their prediction was that $38 \%$ of the 4.7 million eligible uninsured would secure coverage by 2019 with the MCR and only $18 \%$ would obtain coverage without it.

Offering a different point of view, Tanner (2013) did not find ACA to be the most effective mechanism to achieve health care reform and instead offered a market-oriented approach. Tanner analyzed cost and premium projections around ACA and was of the view that the ACA would slow economic growth, increase government expenditure, increase unemployment, increase operational costs for businesses, and hurt small businesses. While ACA would increase the number of Americans with health insurance, he theorized that the country would still fall significantly short of universal coverage, individuals would find it hard to keep their current insurance and medical providers, and would experience increased premiums. The alternative that Tanner proposed was a voluntary, market-based mechanism, such as personal and portable health insurance in the individual market rather than through employer provision, with individuals receiving a standard deduction, a tax credit, or an expanded version of health savings accounts (HSA) for the purchase of 
health insurance. Tanner also proposed increasing competition in the private insurance market, tackling Medicare costs by fixing an amount per recipient using a voucher to help elders purchase private health insurance, and encouraging the fee-for-service payment system that rewards inputs rather than outcomes. Tanner also proposed treating Medicaid like other welfare programs, by imposing work requirements, time limits, tougher eligibility requirements, experimenting with new delivery and reimbursement models, including subsidizing private insurance for the poor as well as using block grants to cap Medicaid spending.

Yaskewich (2015) looked at an unintended effect of the ACA's expansion to cover dependent children to age 26 on college enrollment as well as effects of mandates on health insurance status, using variations across states in dependent age laws. Most dependent age laws also required college enrollment or unmarried status for children to claim dependent status on their parents' health insurance coverage. With ACA, the requirement to enroll in college was not necessary. Yaskewich specifically studied this change in law on college enrollment (or inversely "college lock") as well as insurance coverage. The study compared New Jersey with more generous dependent age laws to Pennsylvania with stricter laws. There was an overall expansion in health coverage among youth in New Jersey. Proportion of uninsured among fulltime students fell by a magnitude of 6.4 percentage points (or $49.2 \%$ ). On the other hand, college enrollment in New Jersey fell by 2 percentage points (or $4 \%$ ) compared to Pennsylvania. Evidence of a weakening in college lock was strongest among young adults living in upper-income households and with a parent receiving employer-sponsored insurance. For young adults in low-income households, there was an increase in college enrollment. The college-lock effect was stronger among males and those who reported having a health problem that made some aspect of daily living more difficult. This study was a nice extension of the"job lock" phenomenon as a result of employer sponsored health insurance system in the US. Richard (2016) found that number of dependent children increased family medical debt, and this was particularly burdensome for those in middle-income families. He posited that dependent care expansion under ACA would help these families considerably. This idea is important and warrants further study.

\section{Discussion and Conclusion}

The contributions to the health literature of JFEI papers over the past decade were numerous, addressing a wide range of topics including health care access and related financial burden on families, chronic/non-communicable diseases across the lifespan, childhood obesity, elder care and nutrition, and policy evaluation of health, nutrition and national health insurance programs. Studies found significant gender differences in the mental and physical health status of the elderly and in health seeking behaviors of migrants. The onset of financial stress leads to smoking for men but not for women. However, women resort to social interactions or unhealthy eating to cope with stress. Studies show indirect consequences such as spillover impacts of extending dependent age laws on college enrollments as well as impact of anti-abortion criminal activities on the supply of abortion services. Strong evidence emerged, of positive impacts of health insurance literacy programs seen to favorably impact younger people and African Americans the most.

Many of the papers acknowledged that results were associations and not causal. Often the samples used were small with not enough power for statistical significance or non-random samples fraught with selection bias or localized samples that had limited generalizability. Many studies were cross-sectional and could not lend the longitudinal and long-term lens. Some studies were able to correct for endogeneity resulting from self-selection using appropriate methods such as instrumental variable approach while some acknowledged that they could not correct for selection bias, recall or reporter bias or omitted variable bias. While the questions have clearly been valuable and have made significant contribution to the literature, methodological improvements and rigorous sensitivity analyses would make the findings more robust.

Looking ahead, some of these studies could be updated using panel or longitudinal data, by lengthening the study periods or even checking for robustness by replicating across various cultures and contexts. Some of the questions that remain unexplored are topics around obesity, socio-economic inequities, financial burden, substance abuse and mental health. For example, examining critical periods of youth obesity or age specific protective factors, impact of soda or snack food tax on low-income populations, racial differences in mental health status, effectiveness of culturally sensitive tobacco and alcohol control policies, or barriers to successful transition from welfare to work remain understudied.

A critical line of research that has not made it to this journal is studies on communicable diseases, which is a germane topic in current times. Even though influenza kills thousands of people in the US each year (Reed et al. 2015), infectious diseases get little attention and has been mostly perceived as a problem of the developing world. This needs to be revisited and more attention paid to research around the impacts of potential global pandemics so that policy solutions can aim to keep the public health systems and the government ready for disastrous events such as the COVID-19 pandemic. Some key papers that looked at impacts of global pandemics estimated that a global influenza pandemic would cost the world $\$ 800$ billion, kill millions of people (Garrett 2007), result 
in school closures and social distancing yielding almost $8 \%$ loss to GDP (Keogh-Brown et al. 2010) with deaths strongly correlated with race, income and place of residence (Garrett 2007). McKibbin and Fernando (2020) laid out all the possible shocks to the various economic sectors due to COVID-19 and indicated that global cooperation with more investment in public health in both the poorest as well as the richest countries would be necessary to prevent a costly global pandemic of this nature in the future. Research examining the impact of COVID-19 or other infectious diseases on social and economic issues of the family would be appropriate and timely for JFEI.

Finally, papers that are concerned with the impact of institutional and structural racism on family dynamics and physical and mental health of men, women and children are absent from JFEI. This would be a worthwhile direction for future researchers to consider.

Acknowledgement I would like to gratefully acknowledge the diligent research assistance provided by our graduate student, Chisom Onyishi.

Funding NA.

\section{Compliance with Ethical Standards}

Conflict of interest The author declare that she have no conflict of interest.

\section{References}

Abarca-Gómez, L., Abdeen, Z. A., Hamid, Z. A., Abu-Rmeileh, N. M., Acosta-Cazares, B., Acuin, C., et al. (2017). Worldwide trends in body-mass index, underweight, overweight, and obesity from 1975 to 2016: A pooled analysis of 2416 population-based measurement studies in 128.9 million children, adolescents, and adults. The Lancet. https://doi.org/10.1016/s0140-6736(17)32129-3.

Aksoy, A., Bilgic, A., Yen, S. T., \& Urak, F. (2019). Determinants of household alcohol and tobacco expenditures in Turkey. Journal of Family and Economic Issues, 40(4), 609-622. https://doi. org/10.1007/s10834-019-09619-1.

Bartholomae, S., Russell, M. B., Braun, B., \& McCoy, T. (2016). Building health insurance literacy: Evidence from the Smart Choice Health Insurance ${ }^{\mathrm{TM}}$ program. Journal of Family and Economic Issues, 37(2), 140-155. https://doi.org/10.1007/s1083 4-016-9482-7.

Benson, L., \& Mokhtari, M. (2011). Parental employment, shared parent-child activities and childhood obesity. Journal of Family and Economic Issues, 32(2), 233-244. https://doi.org/10.1007/s1083 4-011-9249-0.

Bitler, M. P., Gelbach, J. B., \& Hoynes, H. W. (2005). Welfare Reform and Health. Journal of Human Resources, XL(2), 309-334. https ://doi.org/10.3368/jhr.xl.2.309

Brandt, S., \& Marie, P. S. (2011). Racial disparities in hospital length of stay for asthma: Implications for economic policies. Journal of Family and Economic Issues, 32(1), 152-169. https://doi. org/10.1007/s10834-010-9201-8.

Capogrossi, K., \& You, W. (2013). Academic performance and childhood misnourishment: A quantile approach. Journal of Family and Economic Issues, 34(2), 141-156. https://doi.org/10.1007/ s10834-012-9315-2.

Chaloupka, F. J. (2013). Maximizing the public health impact of alcohol and tobacco taxes. American Journal of Preventive Medicine, 44(5), 561-562.

Chang, H. H., Nayga, R. M., \& Chan, K. C. (2011a). Gendered analyses of nutrient deficiencies among the elderly. Journal of Family and Economic Issues, 32(2), 268-279. https://doi.org/10.1007/s1083 4-010-9241-0.

Chang, K. L., Langelett, G. L., \& Waugh, A. W. (2011b). Health, health insurance, and decision to exit from farming. Journal of Family and Economic Issues, 32(2), 356-372. https://doi.org/10.1007/ s10834-011-9254-3.

Chen, Z., \& Zhang, Q. (2011). Nutrigenomics hypothesis: Examining the association between food stamp program participation and bodyweight among low-income women. Journal of Family and Economic Issues, 32(3), 508-520. https://doi.org/10.1007/s1083 4-010-9233-0.

Chen, Z., Yen, S. T., \& Eastwood, D. B. (2005). Effects of food stamp participation on body weight and obesity. American Journal of Agricultural Economics, 87, 1167-1173.

Dolan, E. M., \& Mokhtari, M. M. (2013). The Patient Protection and Affordable Care Act (ACA): Pros and Cons. Journal of Family and Economic Issues, 34, 1-2. https://doi.org/10.1007/s 1083 4-013-9352-5.

Fan, J. X., Wen, M., Jin, L., \& Wang, G. (2013). Disparities in healthcare utilization in China: Do gender and migration status matter? Journal of Family and Economic Issues, 34(1), 52-63. https://doi. org/10.1007/s10834-012-9296-1.

Fryar, C. D., Carroll, M. D., \& Ogden, C. L. (2016, July 18). Products Health E Stats - Prevalence of Underweight Among Children and Adolescents Aged 2-19 Years: United States, 1963-1965 Through 2013-2014. Centers for Disease Control and Prevention. Centers for Disease Control and Prevention. Retrieved from https://www. cdc.gov/nchs/data/hestat/underweight_child_13_14/underweigh t_child_13_14.htm.

Garrett, Thomas. (2007). Economic Effects of the 1918 Influenza Pandemic Implications for a Modern-day Pandemic. Working paper CA0721.

Gibson, D. (2003). Food Stamp Program participation is positively related to obesity in low income women. Journal of Nutrition, $133,2225-2231$.

Grafova, I. B. (2011). Financial strain and smoking. Journal of Family and Economic Issues, 32(2), 327-340. https://doi.org/10.1007/ s10834-011-9247-2.

Hales, C. M., Carroll, M. D., Fryar, C. D., \& Ogden, C. L. (2020, February 27). Products - Data Briefs - Number 360 - February 2020. Centers for Disease Control and Prevention. Centers for Disease Control and Prevention. Retrieved from https://www.cdc. gov/nchs/products/databriefs/db360.htm.

Hayes, J. T., VanBrackle, A., \& Sigman-Grant, M. (2016). Influence of perceived economic strain on the relationship between caregiver BMI and child BMI. Journal of Family and Economic Issues, 37(2), 172-181. https://doi.org/10.1007/s10834-015-9468-x.

Ho, S. H., \& Hung, W. S. (2013). A study of the health of children born to foreign- and native-born mothers in Taiwan. Journal of Family and Economic Issues, 34(3), 355-368. https://doi.org/10.1007/ s10834-012-9336-X.

Hunn, V., \& Heath, C. J. (2011). Path analysis of welfare use: Depression as a mediating factor. Journal of Family and Economic Issues, 32(2), 341-355. https://doi.org/10.1007/s10834-011-9251-6.

Keogh-Brown, M., Smith, R., Edmunds, J., \& Beutels, P. (2010). The macroeconomic impact of pandemic influenza: Estimates from models of the United Kingdom, France, Belgium and The Netherlands. The European Journal of Health Economics, 11(6), 543-554. 
Kim, S. Y., Hong, G. S., \& Montalto, C. P. (2012). The effect of long-term care insurance on home care use among the disabled elders. Journal of Family and Economic Issues, 33(3), 353-362. https://doi.org/10.1007/s10834-011-9280-1.

Liebertz, S., \& Bunch, J. (2017). Examining the Externalities of Welfare Reform: TANF and Crime. Justice Quarterly, 35(3), 477-504. https://doi.org/10.1080/07418825.2017.1323113.

Lin, Y., Chen, B., Liu, T. C., \& Chen, C. S. (2012). The impact of family structure on utilization of preventive care services among children under national health insurance in Taiwan. Journal of Family and Economic Issues, 33(4), 453-463. https://doi. org/10.1007/s10834-012-9301-8.

McCabe, M. P., \& O'Connor, E. J. (2010). The economic impact of progressive neurological illness on quality of life in Australia. Journal of Family and Economic Issues, 31(1), 82-89. https:// doi.org/10.1007/s10834-009-9177-4.

McKibbin, W. J., \& Fernando, R. (2020, March 2). The global macroeconomic impacts of COVID-19: Seven scenarios. Brookings. Brookings. Retrieved from https://www.brookings.edu/ research/the-global-macroeconomic-impacts-of-covid-19-seven -scenarios/.

Medoff, M. H. (2015). The Impact of antiabortion criminal activities and state abortion policies on abortion providers in the United States. Journal of Family and Economic Issues, 36(4), 570-580. https://doi.org/10.1007/s10834-014-9425-0.

Miller, D. P. (2011). Maternal work and child overweight and obesity: The Importance of timing. Journal of Family and Economic Issues, 32(2), 204-218. https://doi.org/10.1007/s 1083 4-010-9244-x.

Monheit, A. C., \& Vistnes, J. (2015). Does public health insurance for children improve single mothers' health care use? Journal of Family and Economic Issues, 36(4), 581-592. https://doi.org/10.1007/ s10834-014-9430-3.

Murasko, J. E. (2015). The age profile of the income-health gradient: An evaluation of two large cohorts of contemporary US children. Journal of Family and Economic Issues, 36(2), 289-298. https:// doi.org/10.1007/s10834-014-9396-1.

Narain, K., \& Ettner, S. (2017). The impact of exceeding TANF time limits on the access to healthcare of low-income mothers. Social Work in Public Health, 32(7), 452-460. https://doi. org/10.1080/19371918.2017.1360817.

Narain, K., Bitler, M., Ponce, N., Kominski, G., \& Ettner, S. (2017). The impact of welfare reform on the health insurance coverage, utilization and health of low education single mothers. Social Science \& Medicine, 180, 28-35. https://doi.org/10.1016/j.socsc imed.2017.03.021.

Ogden, C. L., Fakhouri, T. H., Carroll, M. D., Hales, C. M., Fryar, C. D., Li, X., et al. (2017). Prevalence of obesity among adults, by household income and education-United States, 2011-2014. MMWR. Morbidity and Mortality Weekly Report, 66(50), 13691373. https://doi.org/10.15585/mmwr.mm6650a1.

Ponthiere, G. (2011). Mortality, family and lifestyles. Journal of Family and Economic Issues, 32(2), 175-190. https://doi.org/10.1007/ s10834-010-9229-9.

Reed, C., Chaves, S. S., Kirley, P. D., Emerson, R., Aragon, D., Hancock, E. B., et al. (2015). Estimating influenza disease burden from population-based surveillance data in the United States. PLOS ONE. https://doi.org/10.1371/journal.pone.0118369.

Richard, P. (2016). The burden of medical debt faced by households with dependent children in the United States: Implications for the Affordable Care Act of 2010. Journal of Family and Economic Issues, 37(2), 212-225. https://doi.org/10.1007/s1083 4-016-9491-6.

Roby, D. H., Watson, G., Jacobs, K., Graham-Squire, D., Kinane, C. M., Gans, D., et al. (2013). Modeling the impact of the Affordable
Care Act and the individual mandate on Californians. Journal of Family and Economic Issues, 34(1), 16-28. https://doi. org/10.1007/s10834-012-9349-5.

Ruiz, J. M., Steffen, P., \& Smith, T. B. (2013). Hispanic mortality paradox: A systematic review and meta-analysis of the longitudinal literature. American Journal of Public Health. https://doi. org/10.2105/ajph.2012.301103.

Scholder, S. V. H. K. (2008). Maternal employment and overweight children: Does timing matter? Health Economics, 17(8), 889-906. https://doi.org/10.1002/hec.1357.

Shin, S., \& Kim, H. (2018). Health trajectories of older Americans and medical expenses: Evidence from the Health and Retirement Study data over the 18 year period. Journal of Family and Economic Issues, 39(1), 19-33. https://doi.org/10.1007/s1083 4-017-9542-7.

Tanner, M. (2013). The Patient Protection and Affordable Care Act: A dissenting opinion. Journal of Family and Economic Issues, 34(1), 3-15. https://doi.org/10.1007/s10834-013-9350-7.

Tolbert, J., Orgera, K., Singer, N., \& Damico, A. (2019, December 13). Key Facts about the Uninsured Population. Retrieved from https ://www.kff.org/uninsured/issue-brief/key-facts-about-the-unins ured-population/

Vaughn, C. N. (2019). Essays on child well-being and the social safety net. Theses and Dissertations-Economics, 43. Retrieved from https://uknowledge.uky.edu/economics_etds/43

Witt, W. P., Litzelman, K., Mandic, C. G., Wisk, L. E., Hampton, J. M., Creswell, P. D., et al. (2011). Healthcare-related financial burden among families in the U.S.: The role of childhood activity limitations and income. Journal of Family and Economic Issues, 32(2), 308-326.

Yaskewich, D. (2015). Dependent health insurance laws and college enrollment: Is there evidence of college lock? Journal of Family and Economic Issues, 36(4), 557-569. https://doi.org/10.1007/ s10834-014-9414-3.

You, W., \& Davis, G. C. (2011). Childhood overweight: Does quality of parental childcare time matter? Journal of Family and Economic Issues, 32(2), 219-232. https://doi.org/10.1007/s 1083 4-011-9245-4.

Zhang, Q., Chen, Z., Diawara, N., \& Wang, Y. (2011). Prices of unhealthy foods, food stamp program participation, and body weight status among U.S. low-income women. Journal of Family and Economic Issues, 32(2), 245-256. https://doi.org/10.1007/ s10834-010-9228-x.

Zimmer, D. M. (2011). The effects of the state children's health insurance program on insurance status and health care utilization of children. Journal of Family and Economic Issues, 32(2), 373-383. https://doi.org/10.1007/s10834-010-9235-y.

Publisher's Note Springer Nature remains neutral with regard to jurisdictional claims in published maps and institutional affiliations.

Anoshua Chaudhuri is a Professor and Department Chair of Economics at San Francisco State University. She received her Ph.D in Economics from the University of Washington, Seattle and Masters from Delhi School of Economics. Dr. Chaudhuri's research has encompassed health, development and family economics with a focus on evaluating impacts of policies and programs on community and household health outcomes with a focus on children and the elderly. She teaches courses on Health Economics Research, Economics of Gender and Microeconomics. Dr. Chaudhuri serves on the Boards of SF State's University Corporation as well as a non-profit mental health agency, Richmond Area Multi-services or Rams. 